\title{
Machine learning models to replicate large-eddy simulations of air pollutant concentrations along boulevard-type streets - Supplementary material
}

This supplementary material contains visualisations for the features used for training the regression models on KU18. Table 1 presents the features. Notice that most features are undefined on points that contain buildings. Note also that these features were computed with the help of auxiliary features that are not listed here, such as is_building, is_inhabited, and is_intersection, which are available in the supplied code. The figure titles correspond to the variable names used in the code.

Table 1: List of features used in the regression models.

\begin{tabular}{|c|c|}
\hline Feature name & Description \\
\hline Building height & Height of the closest building \\
\hline Canopy height & Height of the vegetation canopy \\
\hline Courtyard & $\begin{array}{l}\text { Binary variable indicating presence of a } \\
\text { courtyard }\end{array}$ \\
\hline Direction of closest building & $\begin{array}{l}\text { Direction to the closest building relative } \\
\text { to the wind direction }\end{array}$ \\
\hline Distance to building downwind & $\begin{array}{l}\text { Distance to closest building in the same } \\
\text { direction as the wind }\end{array}$ \\
\hline Distance to building upwind & $\begin{array}{l}\text { Distance to closest building in the di- } \\
\text { rection against the wind }\end{array}$ \\
\hline Height to width ratio & $\begin{array}{l}\text { Height of the closest building relative to } \\
\text { the width of the street }\end{array}$ \\
\hline Pollutant emissions & Emission level \\
\hline $\begin{array}{l}\text { Pollutant emissions convolution, } \\
\sigma=\{1,2,4,8,16\}\end{array}$ & $\begin{array}{l}\text { Gaussian convolution of the emissions } \\
\text { with standard deviation } \sigma\end{array}$ \\
\hline $\begin{array}{l}\text { Pollutant emissions convolution } \\
\text { upwind, } \sigma=\{8,16,32\}\end{array}$ & $\begin{array}{l}\text { Convolution of the emissions upwind } \\
\text { with standard deviation } \sigma\end{array}$ \\
\hline Street & $\begin{array}{l}\text { Binary variable indicating presence of a } \\
\text { street }\end{array}$ \\
\hline Street width & Width of the street \\
\hline
\end{tabular}




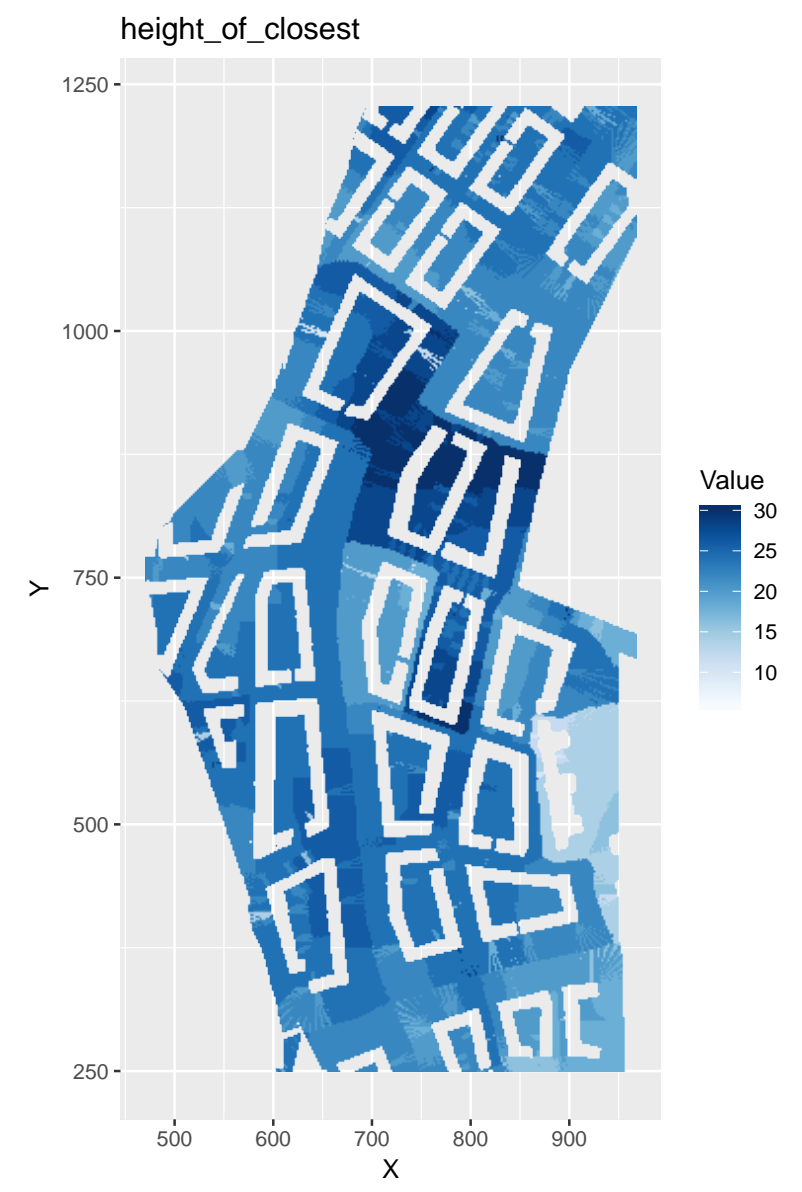

Figure 1: Building height 


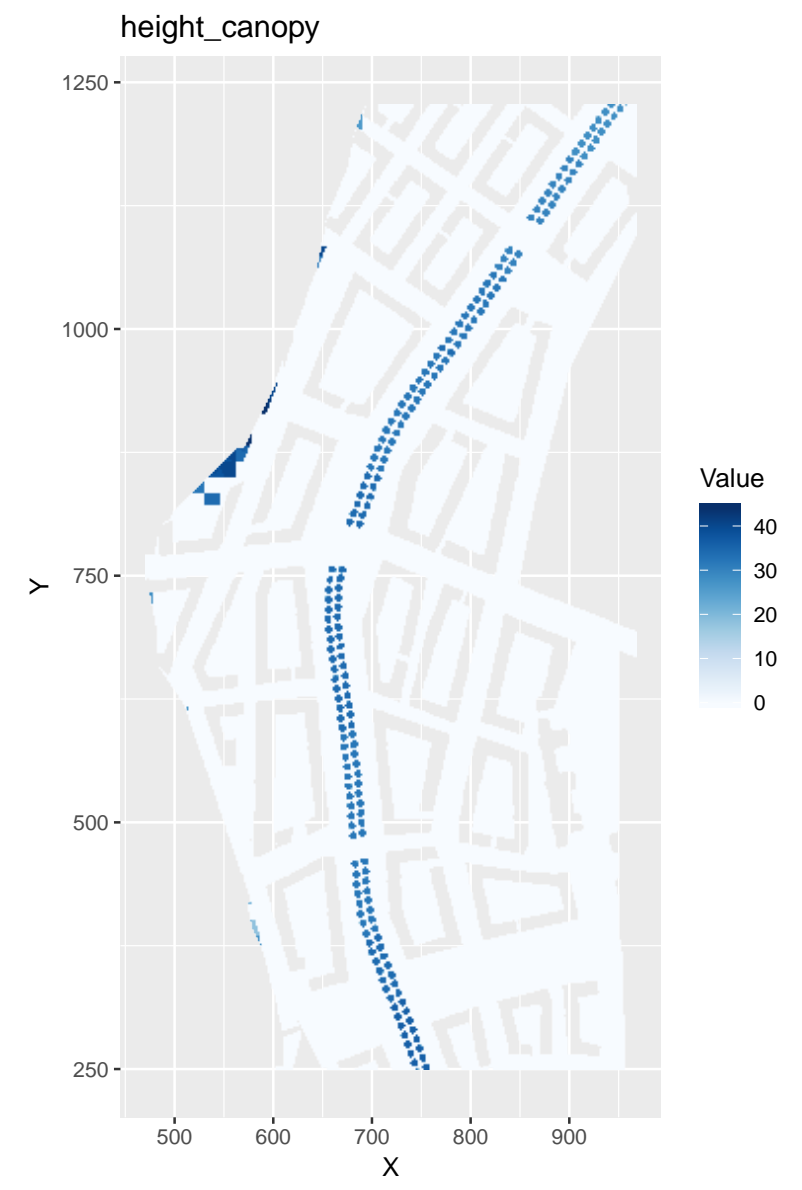

Figure 2: Canopy height 


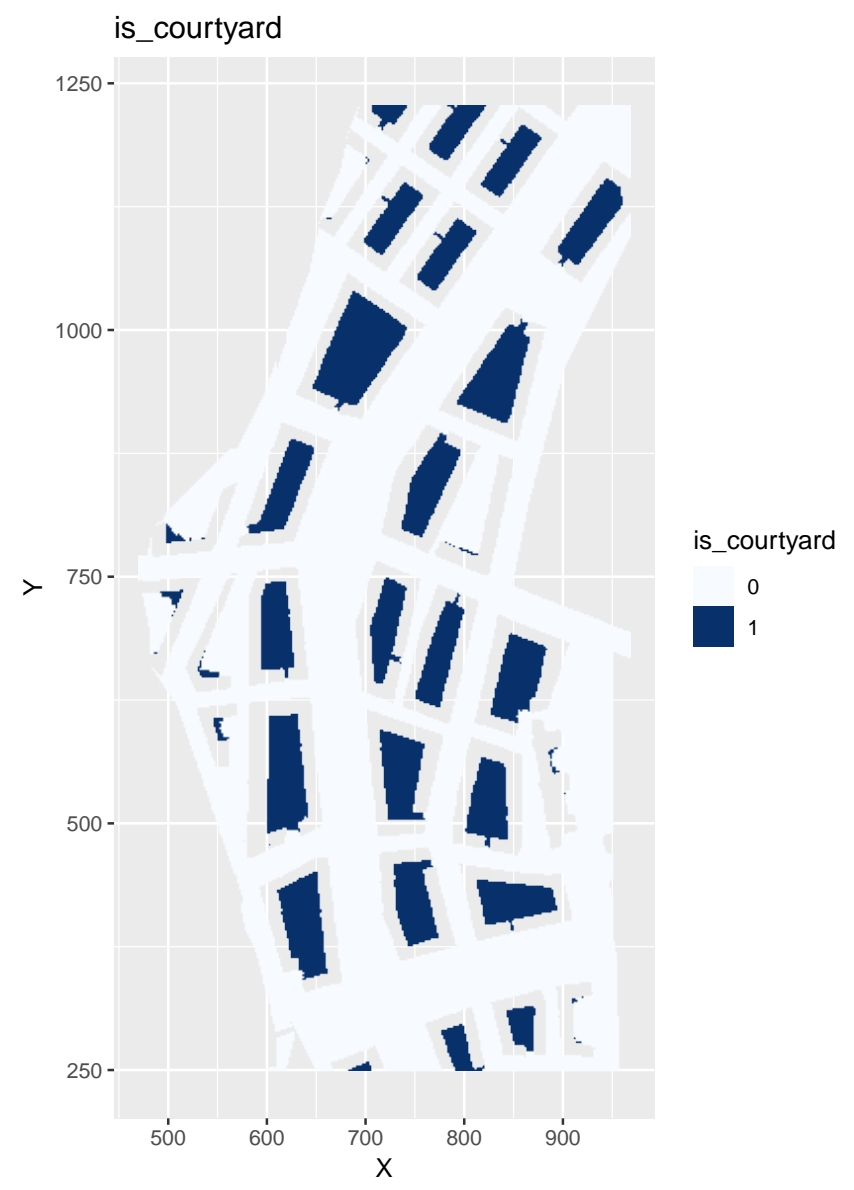

Figure 3: Courtyard 


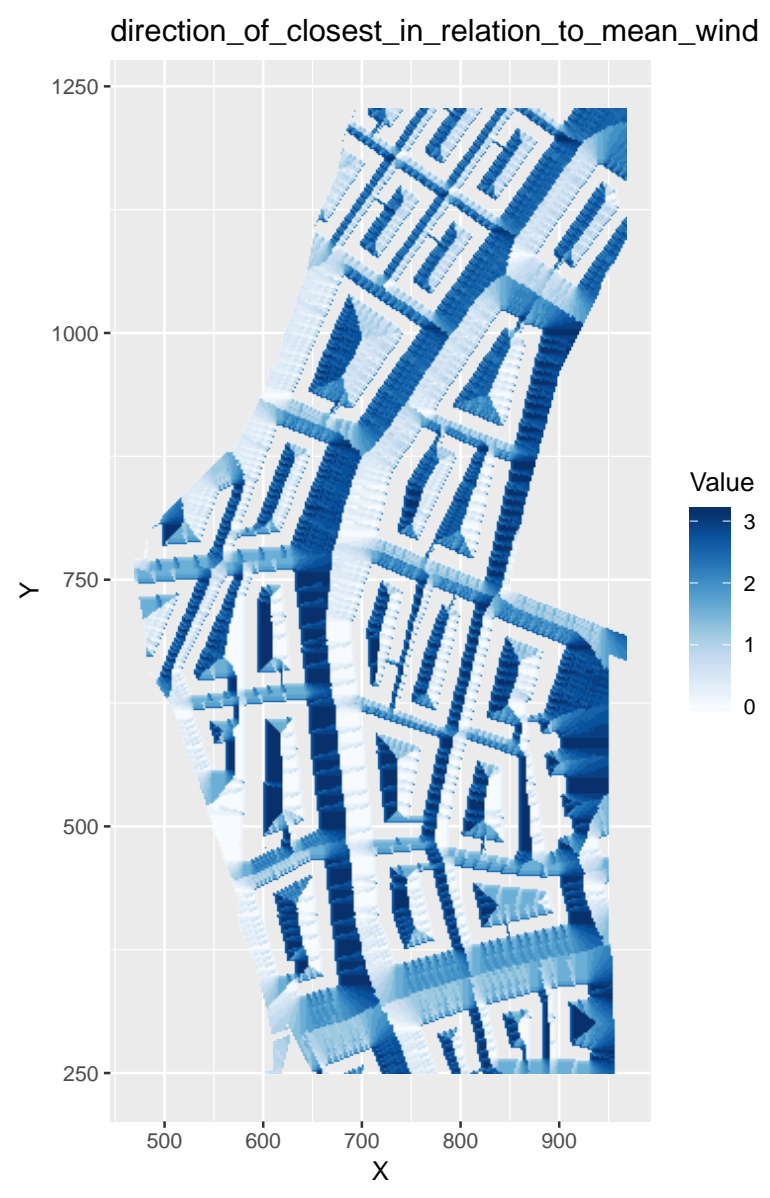

Figure 4: Direction of closest building 


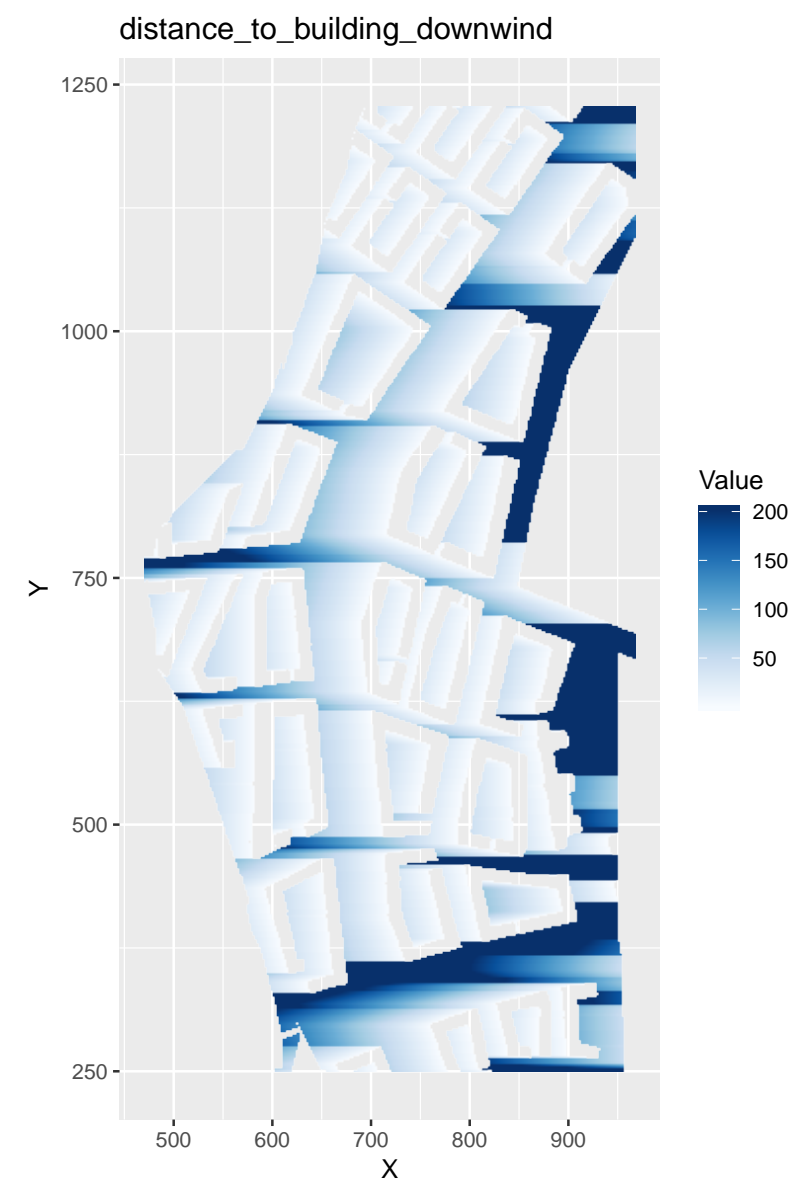

Figure 5: Distance to building downwind. Due to the particulars of the feature generating algorithm, the feature is undefined if the next building is $300 \mathrm{~m}$ away. 


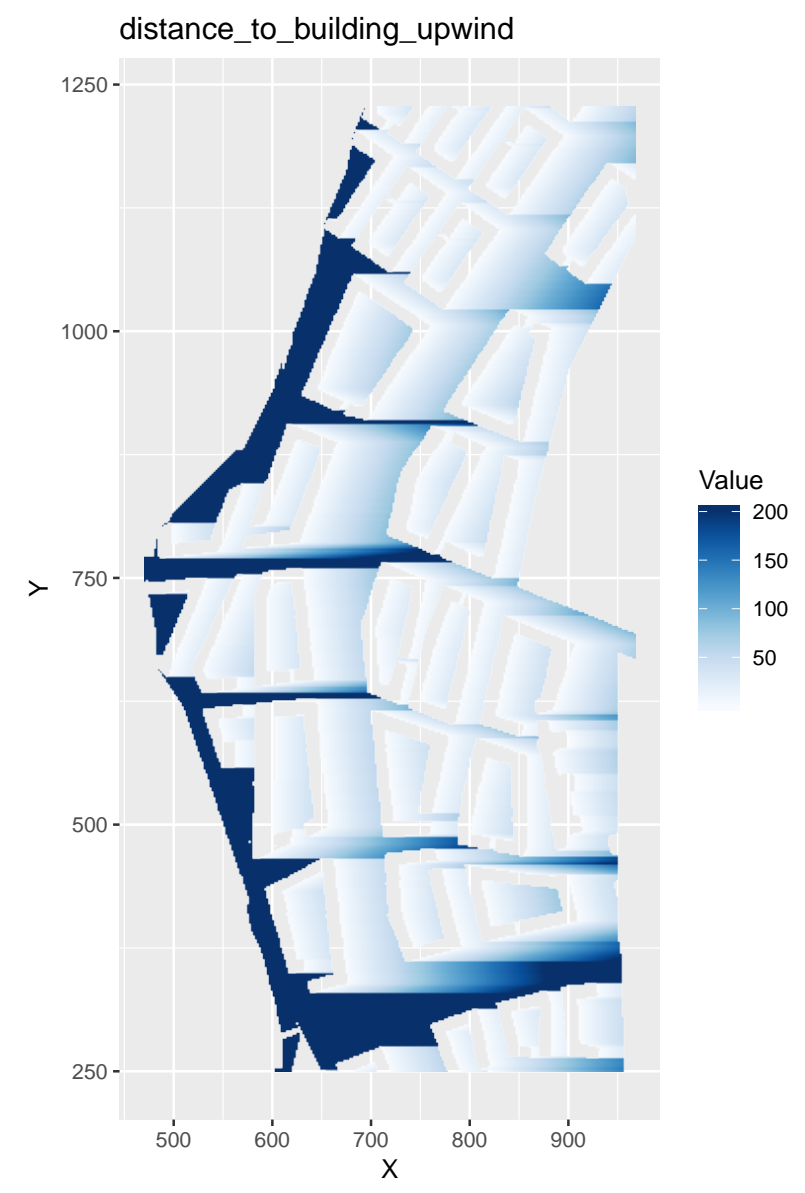

Figure 6: Distance to building upwind. Due to the particulars of the feature generating algorithm, the feature is undefined if the next building is $300 \mathrm{~m}$ away. 


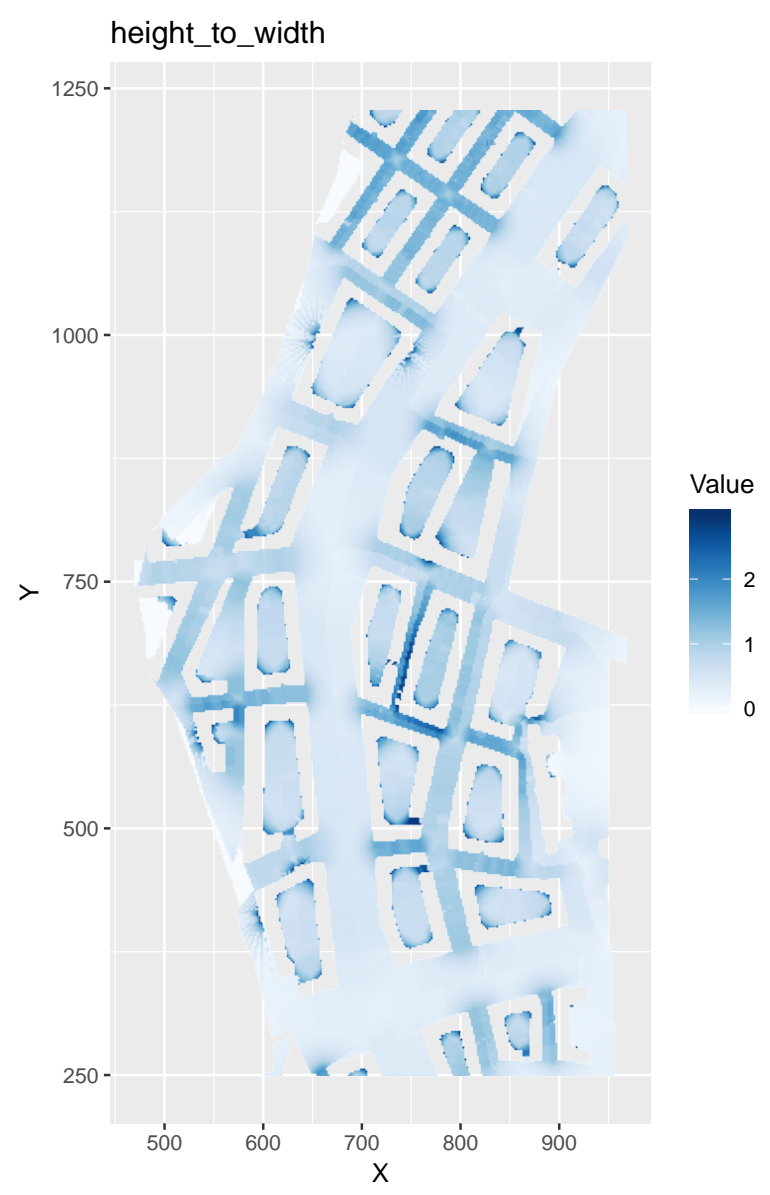

Figure 7: Height to width ratio 


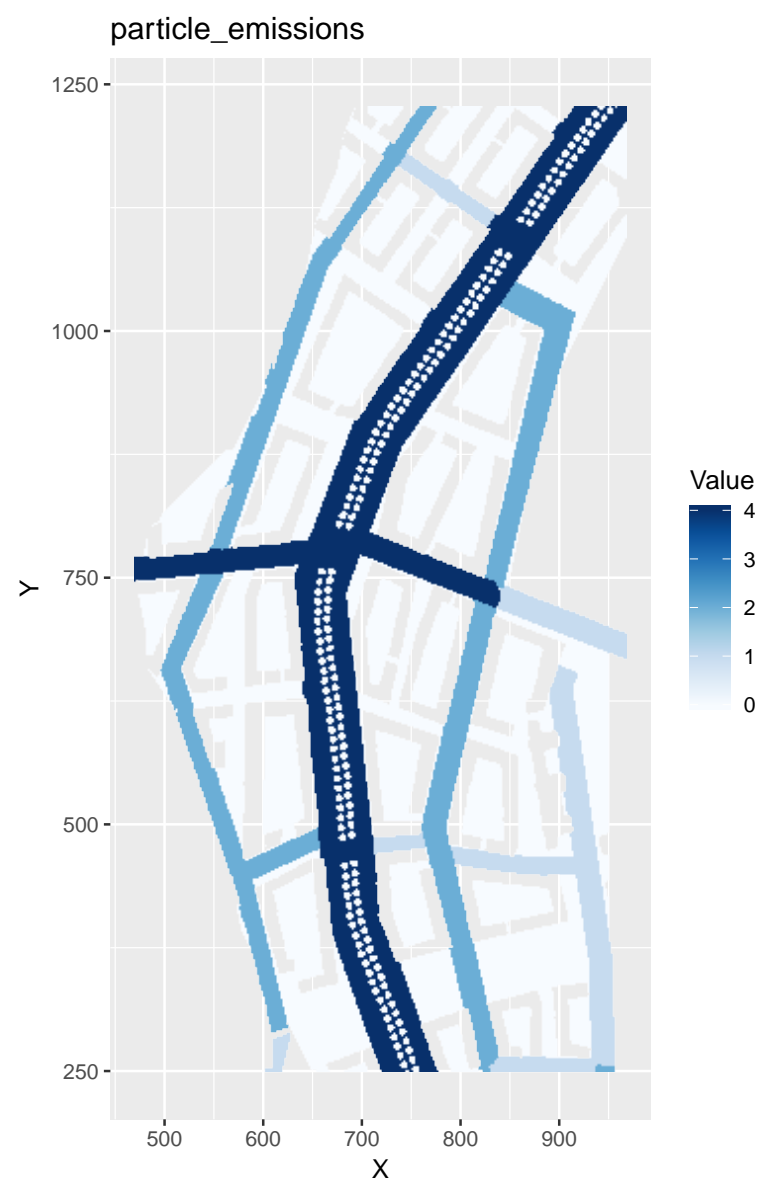

Figure 8: Pollutant emissions 


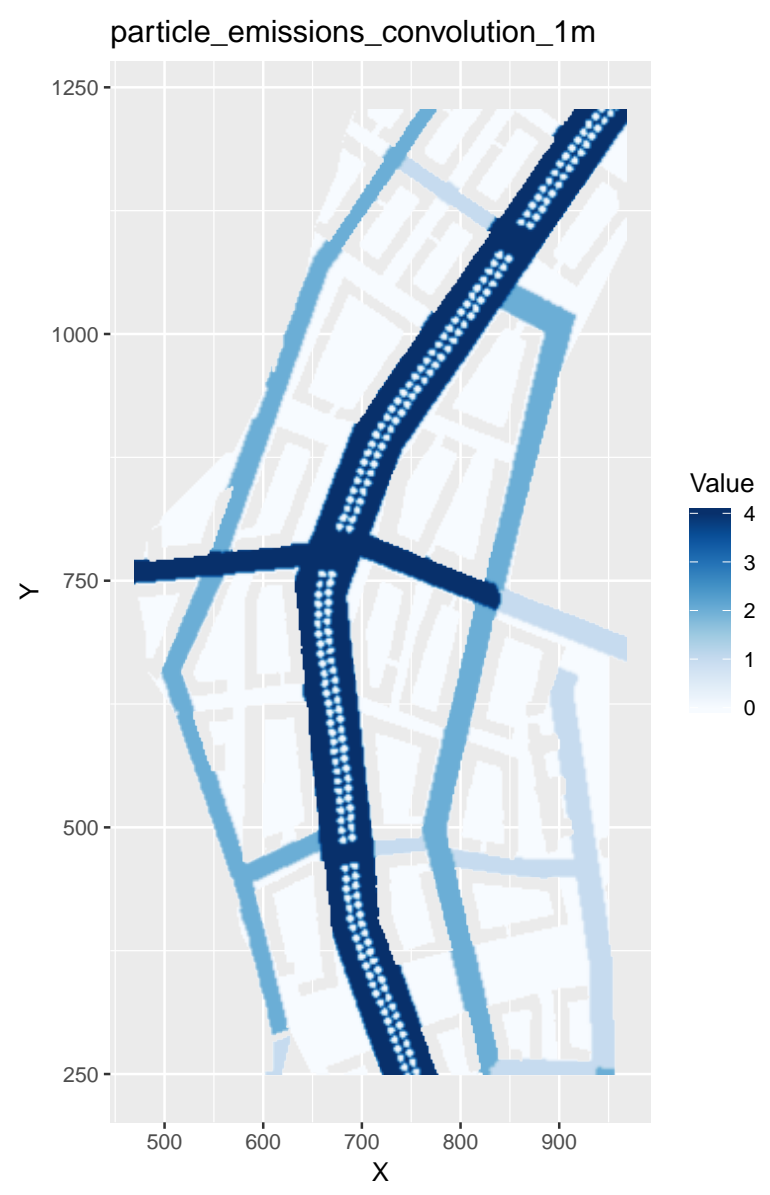

Figure 9: Pollutant emissions convolution, $\sigma=1$ 


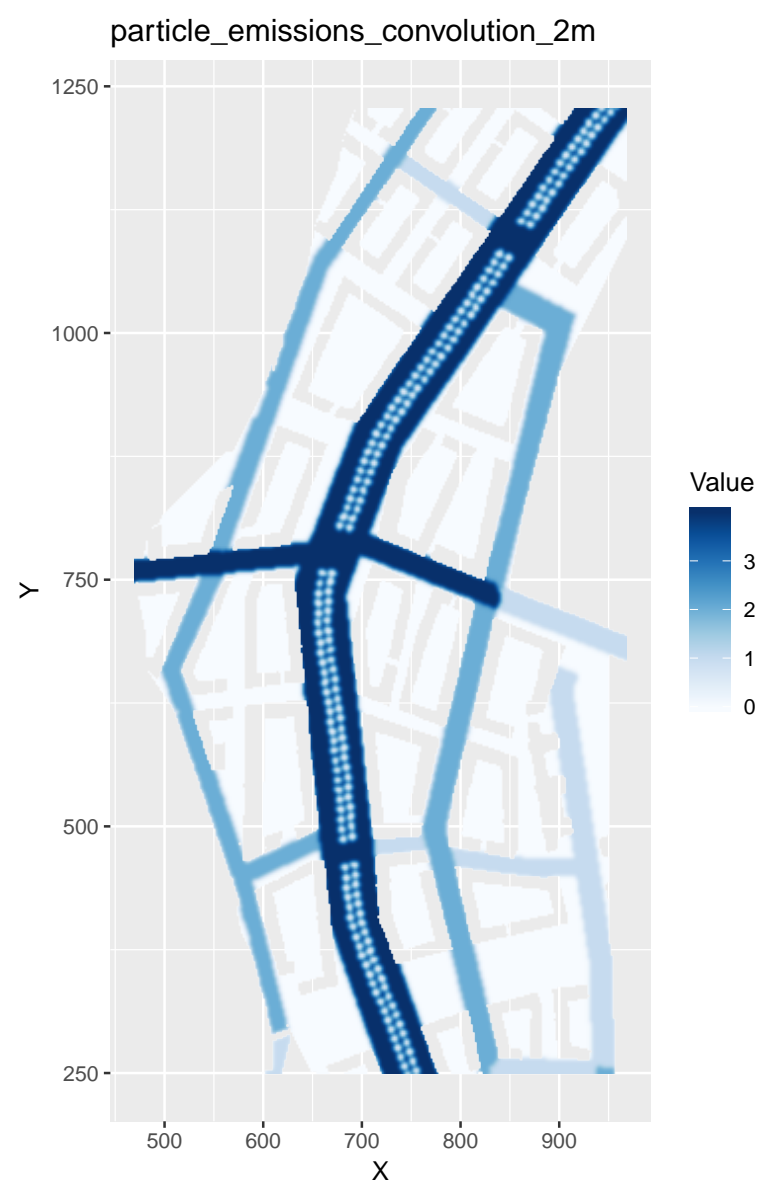

Figure 10: Pollutant emissions convolution, $\sigma=2$ 


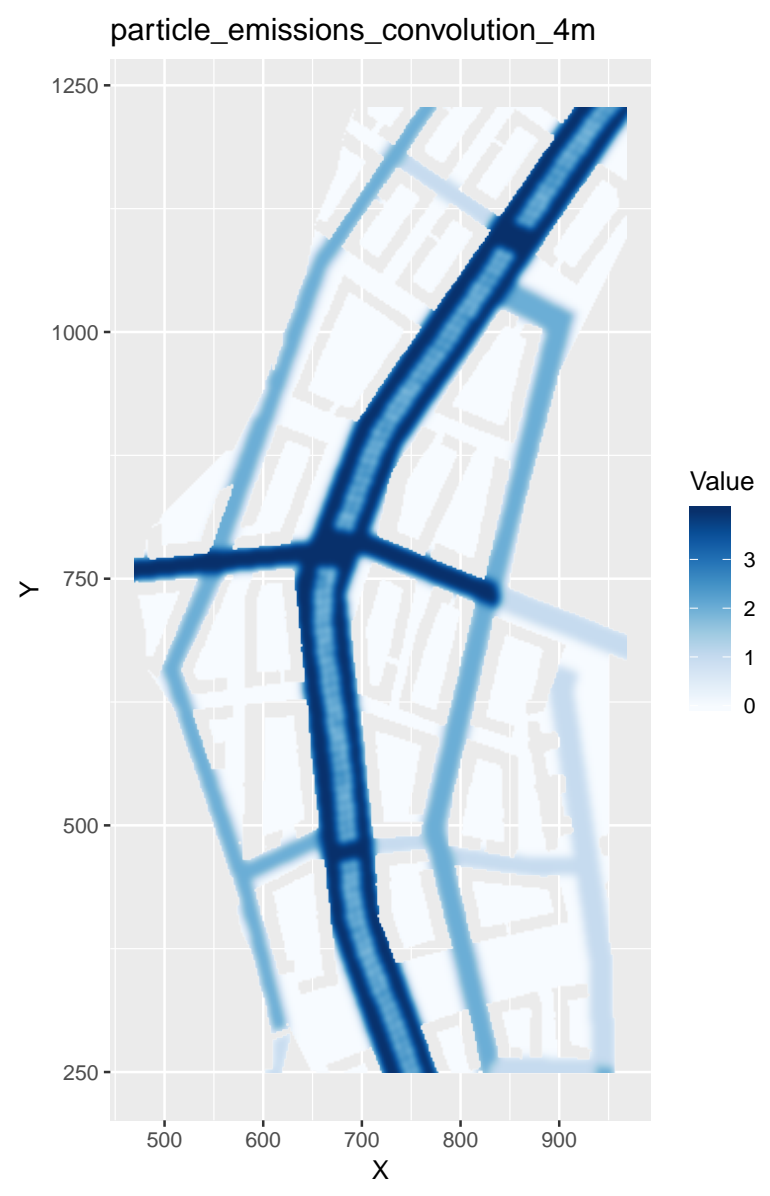

Figure 11: Pollutant emissions convolution, $\sigma=4$ 


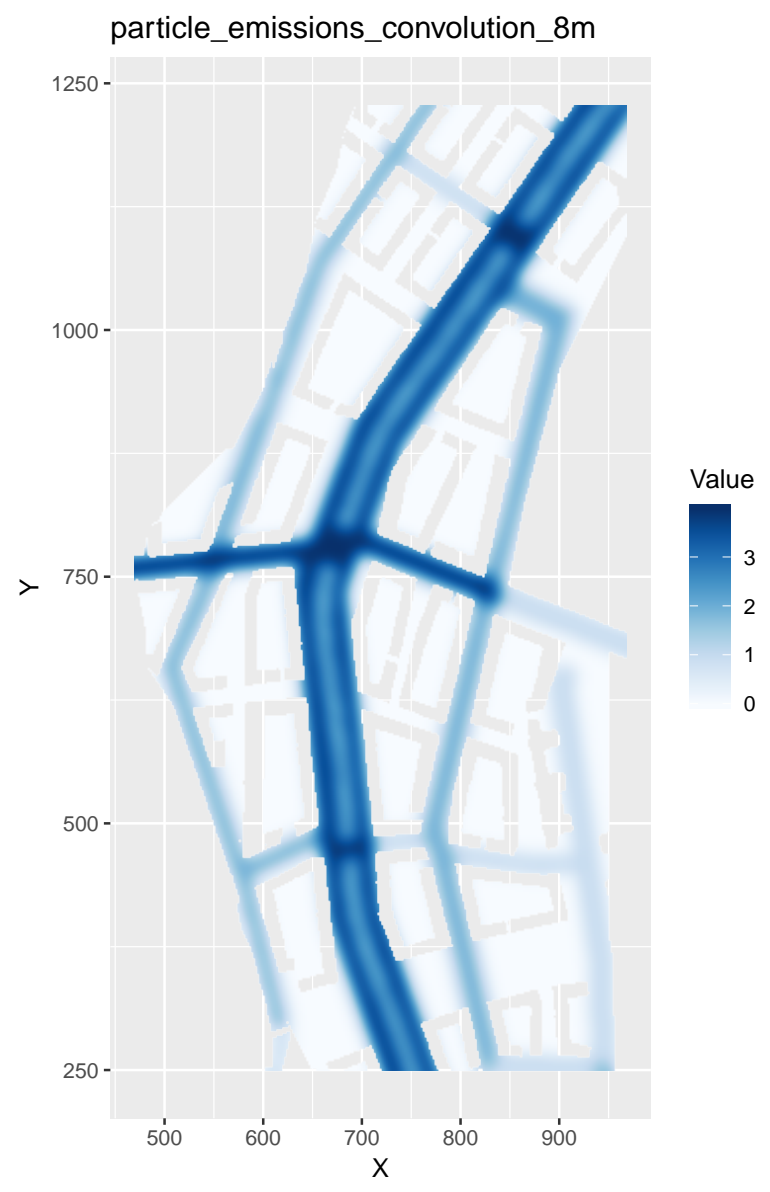

Figure 12: Pollutant emissions convolution, $\sigma=8$ 


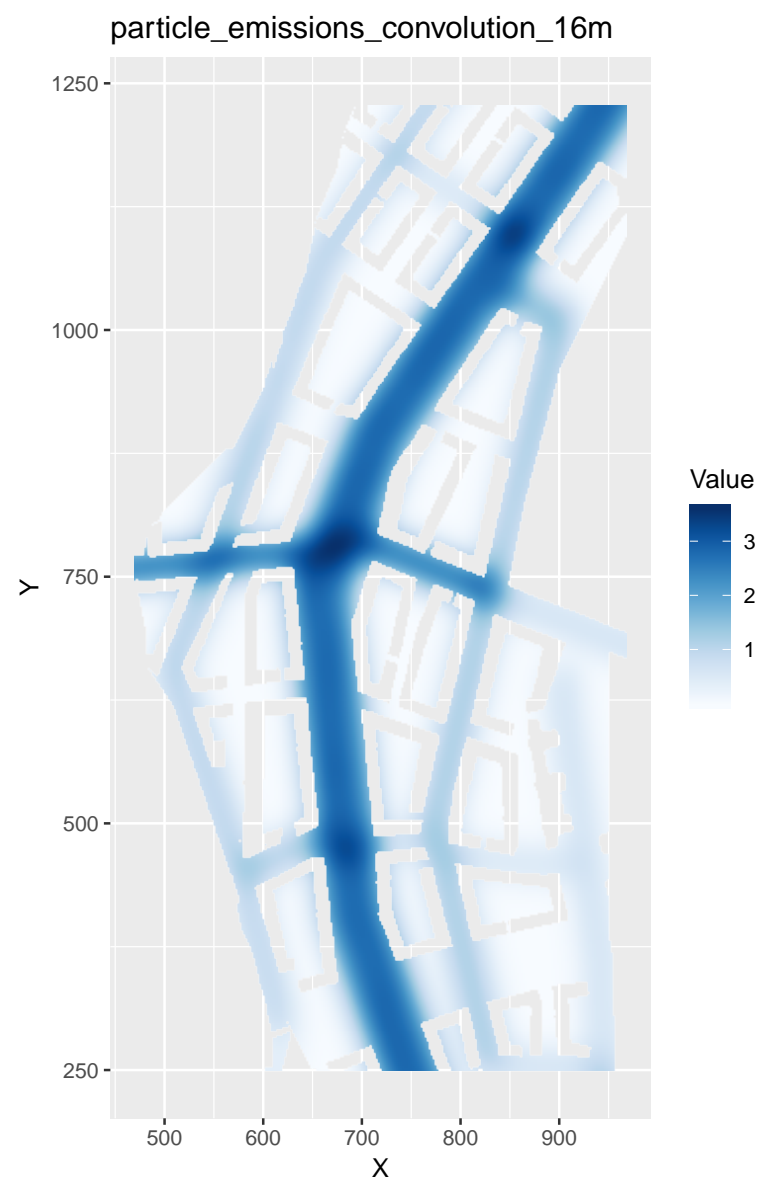

Figure 13: Pollutant emissions convolution, $\sigma=16$ 


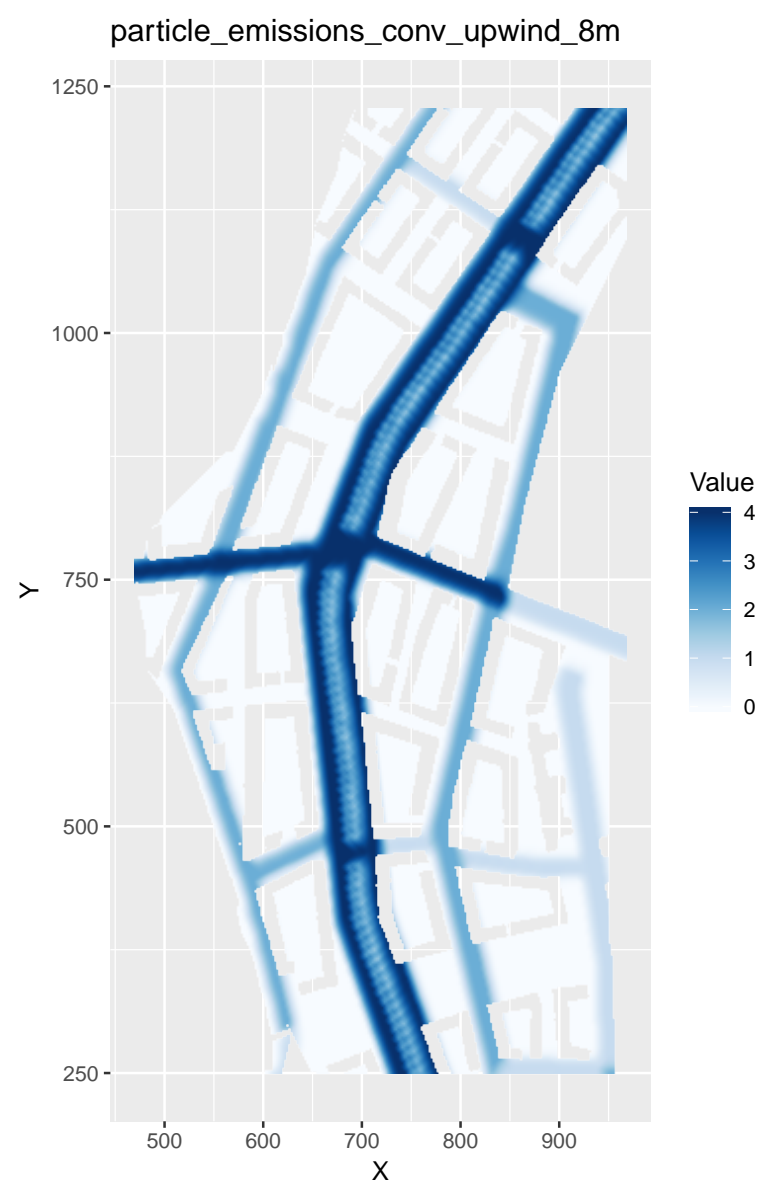

Figure 14: Pollutant emissions convolution upwind, $\sigma=8$ 


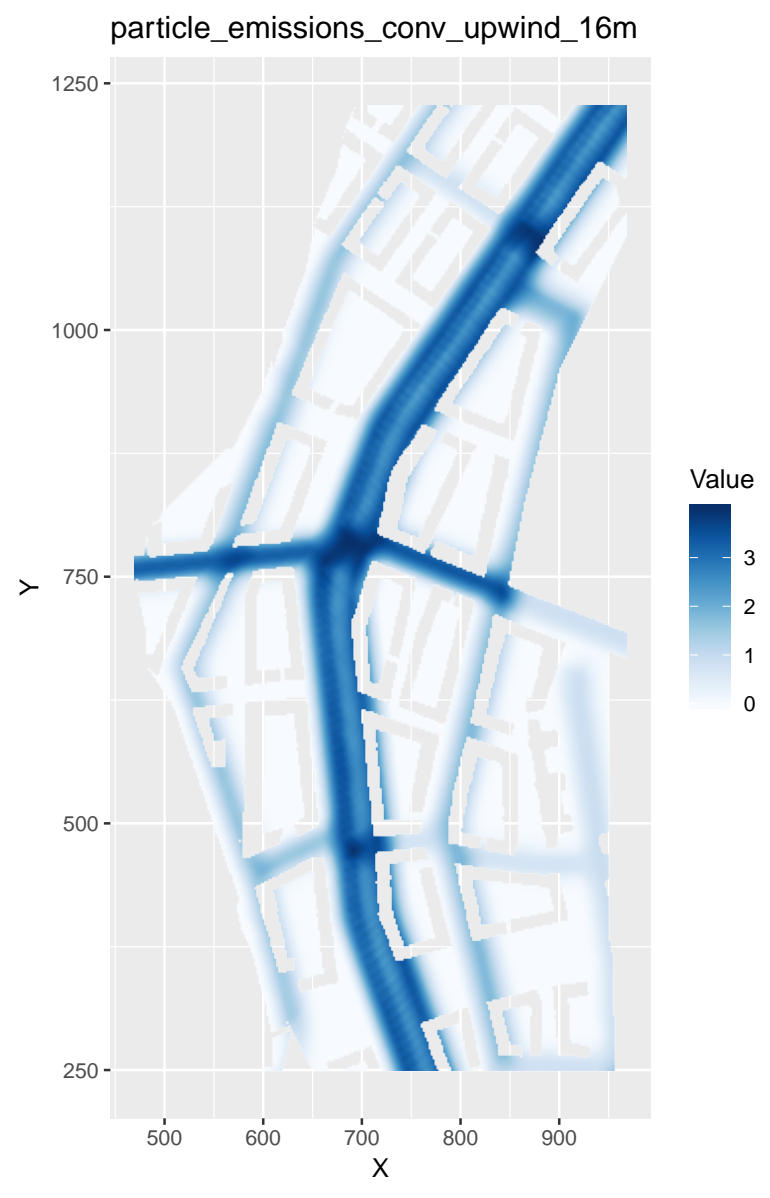

Figure 15: Pollutant emissions convolution upwind, $\sigma=16$ 


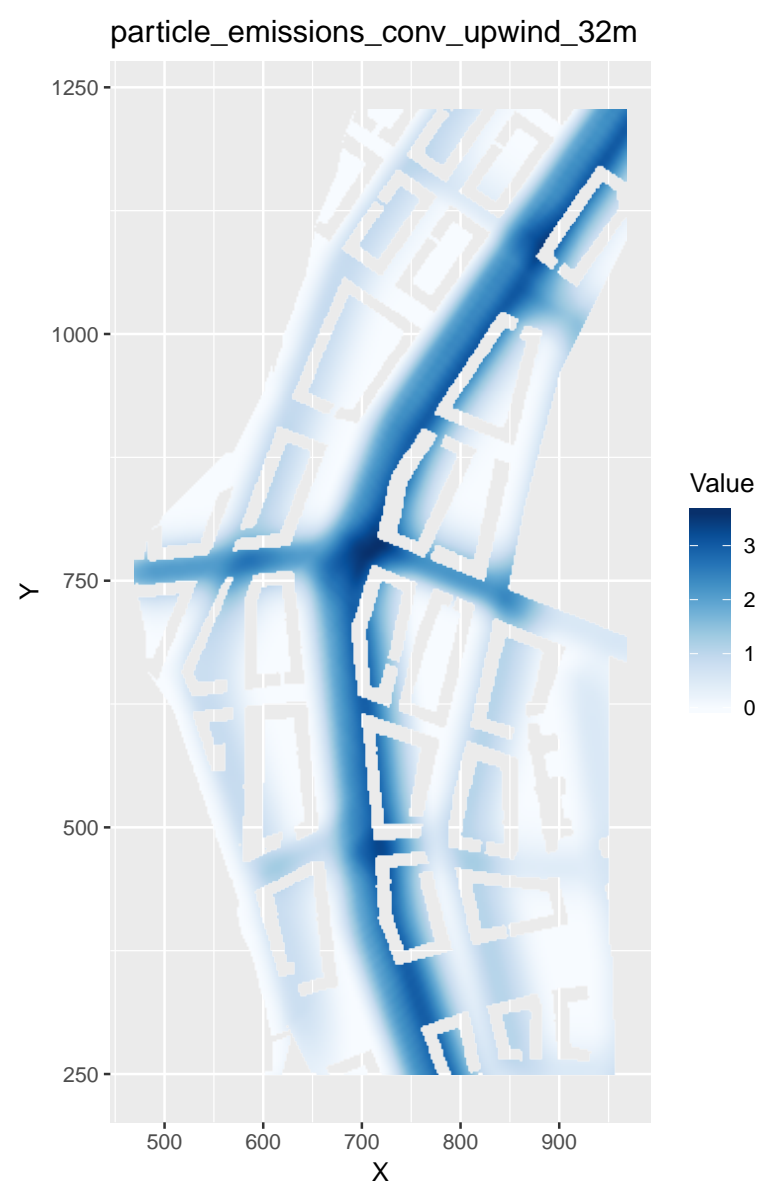

Figure 16: Pollutant emissions convolution upwind, $\sigma=32$ 


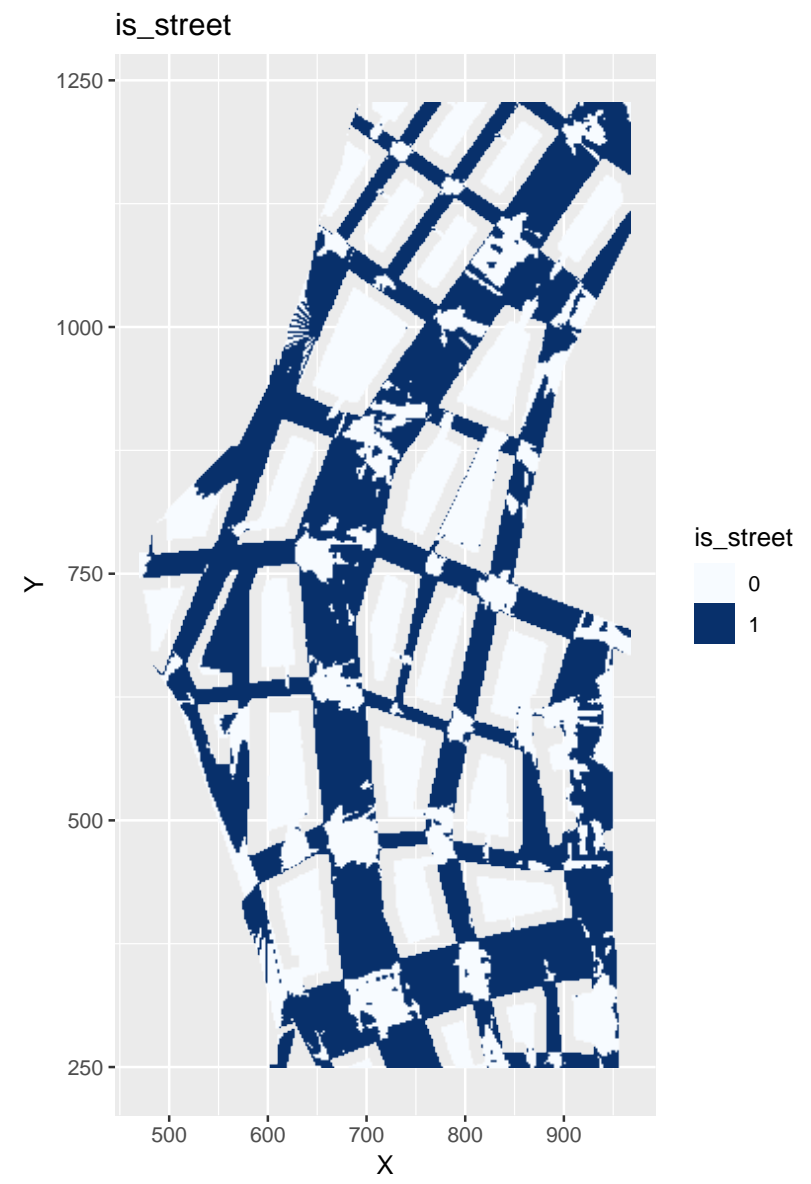

Figure 17: Street 


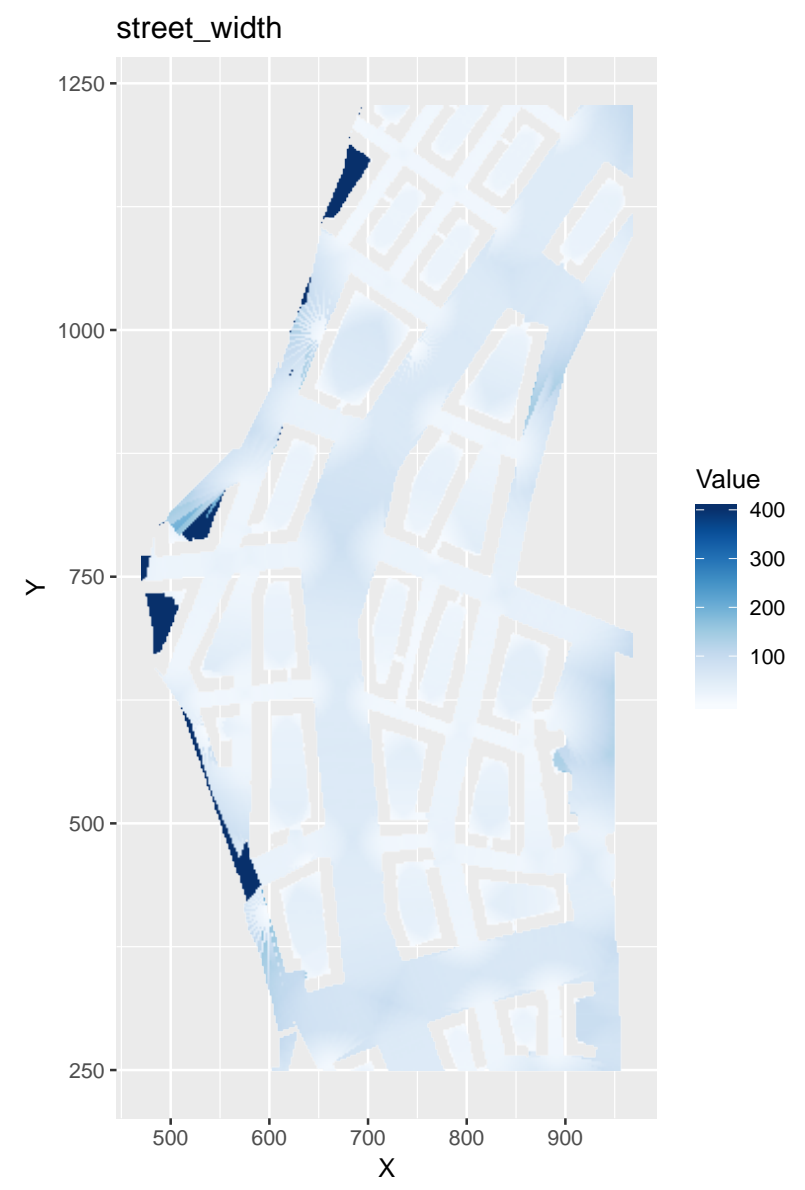

Figure 18: Street width 


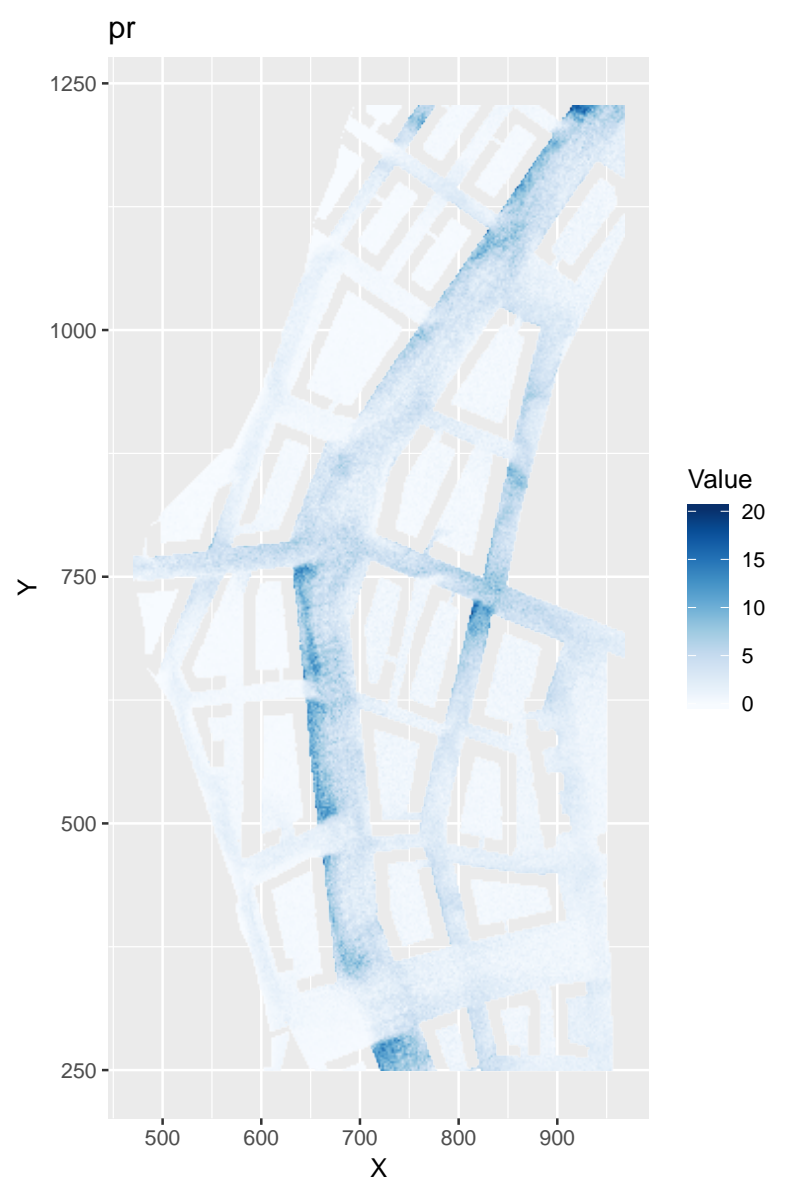

Figure 19: Pollutant concentrations (target variable) 